\title{
Novidades em Vanilla Mill. (Orchidaceae) para a borda sul-amazônica, Estado de Mato Grosso, Brasil
}

\author{
Mathias Erich Engels ${ }^{1,4}$, (1) Lilien Cristhiane Ferneda Rocha ${ }^{2}$ e (1) Ana Kelly Koch ${ }^{3}$
}

Recebido: 07.01.2020; aceito: 24.03.2020

Como citar: Engels, M.E., Rocha, L.C.F. \& Koch, A.K. 2020. Novidades em Vanilla Mill. (Orchidaceae) para a borda sul-amazônica, Estado de Mato Grosso, Brasil. Hoehnea 47: e032020. http://dx.doi.org/10.1590/2236-8906-03/2020.

\begin{abstract}
Novelties in Vanilla Mill. (Orchidaceae) to the South Amazonian border, Mato Grosso State, Brazil). During the study of the genus Vanilla Mill. in the north of the state of Mato Grosso, some specimens of Vanilla bahiana, $V$. cribbiana, and $V$. cristatocallosa were collected, corresponding to new records of geographical distribution for the state. It is presented a taxonomic treatment with descriptions, notes on taxonomic, ecologic and geographic issues, as well as illustrations of species. The analysis of the samples allowed us to reestablish $V$. cristatocallos $a$ as an autonomous taxon which was previously considered a synonym of $V$. cristagalli. Additionally, $V$. aspericaulis, a recently described species, is synonymized with $V$. cristatocallosa.
\end{abstract}

Keywords: Amazon, hemiepiphyte, Neotropics, new records, taxonomy

RESUMO - (Novidades em Vanilla Mill. (Orchidaceae) para a borda Sul-amazônica, Estado de Mato Grosso, Brasil). Durante o estudo do gênero Vanilla Mill. do norte do Estado de Mato Grosso, foram coletados espécimes de Vanilla bahiana, $V$. cribbiana e $V$. cristatocallosa, sendo novos registros de distribuição geográfica para este Estado. É apresentado aqui, o tratamento taxonômico, com descrições, comentários taxonômicos, ecológicos e de distribuição geográfica, bem como ilustração destas espécies. Com as análise desses espécimes foi possível restabelecer V. cristatocallosa como táxon autônomo, anteriormente considerado sinônimo de $V$. cristagalli. Além disso, $V$. aspericaulis, uma espécie recentemente descrita, é sinonimizada em $V$. cristatocallosa.

Palavras-chave: Amazonia, hemiepífita, novas ocorrências, região neotropical, taxonomia

\section{Introdução}

O gênero pantropical Vanilla Mill. possui cerca de 110 espécies (Govaerts 2016), com 34 ocorrendo no Brasil (BFG 2015, 2018). Para o Estado de Mato Grosso, até então era conhecida a ocorrência de dez espécies: Vanilla chamissonis Klotzsch, V. eggersii Rolfe, V. ensifolia Rolfe, V. lindmaniana Kraenzl., V. mexicana Mill., V. palmarum (Salzm. ex Lindl.) Lindl., V. planifolia Jacks. ex Andrews, $V$. pompona Schiede, $V$. ribeiroi Hoehne (BFG 2015, 2018) e $V$. appendiculata Rolfe (Engels \& Ferneda Rocha 2016).
Ao mesmo tempo que há espécies de Vanilla bem conhecidas e bem representadas nas coleções biológicas, há espécies apenas conhecidas pelo material tipo (Fraga 2002). A recoleta de novos materiais ajuda a esclarecer dúvidas ou pontos obscuros sobre a identidade destas espécies pouco conhecidas, bem como pode ampliar a distribuição geográfica das mesmas, já que Vanilla é um gênero moroso quanto à identificação taxonômica e que possui espécies com distribuição disjunta (Fraga 2002, Koch et al. 2013).

Durante o resgate de Flora da Usina Hidrelétrica de Colíder, no rio Teles Pires, Centro Norte do Estado de Mato Grosso, foram coletados espécimes de Vanilla bahiana

1. Assessoria Técnica Ambiental Ltda., Rua Marechal José Bernardino Bormann, 821, Batel, 80730-350 Curitiba, PR, Brasil

2. Juris Ambientis Consultores S/S Ltda., Rua Humberto Costa, 96, Hugo Lange, 80040-150 Curitiba, PR, Brasil

3. Universidade Federal do Mato Grosso, Instituto de Biociências, Departamento de Botânica e Ecologia, Laboratório de Estudos Integrados de Plantas, Avenida Fernando Corrêa da Costa, 2376, Boa Esperança, 78060-900 Cuiabá, MT, Brasil

4. Autor para correspondencia: mathiasengels@hotmail.com 
Hoehne, V. cristatocallosa Hoehne e V. cribbiana Soto Arenas, que ainda não haviam sido citadas para o Estado, ampliando para 13 o número de espécies do gênero no Estado de Mato Grosso. Adicional aos novos registros é esclarecida ainda a circunscrição de $V$. cristatocallosa.

\section{Material e métodos}

Todo o material foi coletado e herborizado segundo Fidalgo \& Bononi (1989) e depositado nos Herbários HERBAM, MBM e TANG, acronimos de acordo com Thiers (2019, continuamente atualizado). A terminologia morfológica foi adotada de acordo com Gonçalves \& Lorenzi (2011). Para a confirmação das identificaçãos foram consultadas as obras originais, e quando possível a imagem do material tipo.

\section{Resultados e discussão}

Vanilla bahiana Hoehne, Arq. Bot. Estado São Paulo, n.s., f.m., 2: 108. 1950. Tipo: BRASIL. Bahia: sem localidade, cultivada em Campinas - Estado de São Paulo. XI-1947, fl., J. Ferreira da Cunha s/n (Holótipo SP 54.661).

Figuras 1-2

Erva hemiepífita, escandente. Raízes ca. $0,2 \mathrm{~cm}$ espessura, cilíndricas, alvacentas. Caule 0,6-0,8 cm espessura, cilíndrico, liso, escandente, verde; entrenós (5) 8-11,7 cm comp. Folhas 11-13 $\times 3-3,5 \mathrm{~cm}$, planas, oblongo-lanceoladas, levemente carnosas, base agudo-cuneada, margem lisa, ápice obtuso. Inflorescência 4,6-6,5 × 0,3-0,4 cm, racemosa, axilar, multiflora (7-12-flora). Flor com ovário+pedicelo 3,1-4 $\times$ 0,5-0,6 cm, cilíndrico, liso, verde claro; sépala dorsal 6,6-6,8 $\times$ 0,9-1,1 cm, estreito-oblanceolada, base aguda, margem inteira, ápice agudo, face abaxial lisa, verde-claras; sépalas laterais 5,9-6,2 × 1,1-1,2 cm, estreito-oblanceolada, base aguda, margem inteira, ápice agudo, face abaxial lisa, verde-claras; pétalas 5,9-6,3 × 0,8-0,9 cm, estreito-oblanceoladas, base aguda, margem inteira, ápice obtuso a agudo, verde-claras; labelo 5,5-5,8 × 2,9-3,2 cm, parcialmente adnato à coluna, âmbito geral elíptico, inconspicuamente trilobado, alvo com ápice amarelo-alaranjado e esverdeado; lobos laterais 3-3,2 $\times$ 0,8-1 cm, elípticos, margem inteira; lobo central ca. $1 \times 1,2$ $\mathrm{cm}$, arredondado, ápice arredondado-acuminado, margem sinuada; carenas velutinas na base, com calos penicilados no centro; calos penicilados 3-4 mm compr. Coluna 4,5-4,7 $\times$ 0,4-0,5 cm, subcilíndrica, densamente pilosa no ventre, da base ao ápice, alva; tricomas ca. $1 \mathrm{~mm}$ compr., alvos. Antera $0,4-0,5 \times 0,4-0,5 \mathrm{~cm}$, séssil, ovoide, alva. Fruto não visto.

Material examinado: BRASIL. MATo Grosso: Itaúba, Resgate de Flora da UHE Colíder, Lote G de supressão, 10-X-2015, fl., M.E. Engels 3755 (HERBAM, MBM).

Vanilla bahiana é endêmica do Brasil, ocorre na região Sudeste, Estados de São Paulo, Espirito Santo, Rio de Janeiro e Minas Gerais; Região Nordeste, na Bahia,
Sergipe, Alagoas, Pernambuco, Paraíba, Rio Grande do Norte e Maranhão; e na região Centro-Oeste apenas no Distrito Federal (Ferreira et al. 2017; BFG 2015; Ferreira et al. 2017; BFG 2018) e, no presente trabalho, tem sua ocorrência confirmada para o Estado de Mato Grosso, onde a mesma vinha sendo tratada como $V$. pompona Schiede (eg. Petini-Benelli \& Vaz-de-Melo 2013).

No Estado de Mato Grosso foi encontrada na Floresta Estacional Sempre Verde às margens do rio Teles Pires, na região Centro Norte do Estado, área de ecótono entre os domínios Amazônico e Cerrado. Suas ramagens chegam da copa do bosque ao dossel. Floresceu em cultivo no mês de outubro.

Pode ser reconhecida pelas folhas oblongo-lanceoladas, flores com sépalas e pétalas verdes e labelo alvo com ápice amarelo-alaranjado-esverdeado, inconspicuamente trilobado com base velutina, margem do lobo central sinuada e coluna com ventre piloso.

Vanilla cribbiana Soto Arenas, Lankesteriana 9: 300. 2010. Tipo. MEXICO. Chiapas. Mpio. Ocosingo, Estación de Biología Chajul, en el borde del Río Lacatúm; a 680 m del Puente Hamaca, por la vereda a Arroyo Miranda. 20-VI-1996, M.Soto \& R.Solano 7945 (Holótipo AMO; Isótipos: K, AMO (álcool)).

Figuras 3-4

Erva hemiepífita, escandente. Raízes $0,2-0,3 \mathrm{~cm}$ espessura, cilíndricas, castanhas. Caule $0,5-0,7 \mathrm{~cm}$ espessura, cilíndrico, liso, escandente, verde; entrenós 9,4-12,1 cm compr. Folhas 25,1-28,2 × 5-5,7 cm, planas, elípticas a estreitamente oblanceoladas, coriáceas, base aguda, ápice agudo. Inflorescência ca. $13 \times 0,3 \mathrm{~cm}$, racemosa, axilar, multiflora (25-flora). Flor com ovário+pedicelo ca. 4,2 ×0,6 $\mathrm{cm}$, cilíndrico, papiloso, verde; sépala dorsal ca. $5,2 \times 1 \mathrm{~cm}$, elíptica, base aguda, margem inteira, ápice agudo-cuculado, face abaxial papilosa, amarela; sépalas laterais ca. 4,8 × 1,1 $\mathrm{cm}$, elíptico-oblanceoladas, base aguda, margem inteira, ápice agudo-cuculado, face abaxial papilosa, amarelas; pétalas ca. 4,6 × 1,1-1,2 cm, elíptico-oblanceoladas, base aguda, margem inteira, ápice obtuso, amarelas; labelo ca. 4,7 × 2,8 $\mathrm{cm}$, parcialmente adnato à coluna, âmbito geral oblanceolado a oboval, trilobado, alaranjado; lobos laterais ca. 1,6 × 0,9$1,0 \mathrm{~cm}$, obovais, margem inteira a levemente sinuada; lobo central ca. $0,8 \times 1,1 \mathrm{~cm}$, largo subdeltoide, ápice retuso, margem sinuada; carena central velutina na base, com calos penicilados no centro e espessado-calosa no centro do terço apical; calos penicilados ca. $4 \mathrm{~mm}$ compr. Coluna ca. 3, $2 \times$ $0,4 \mathrm{~cm}$, subcilíndrica, densamente pilosa no ventre, da base até metade, alvo amarelada; tricomas ca. $0,5 \mathrm{~mm}$ compr., alvos. Antera ca. $0,3 \times 0,3 \mathrm{~cm}$, séssil, arredondada, alva. Fruto imaturo ca. $12,5 \times 1 \mathrm{~cm}$, cilíndrico, verde.

Material examinado: BRASIL. MATo Grosso: Itaúba, Resgate de Flora da UHE Colíder, Lote G de supressão, 20-VI-2015, fl., M.E. Engels 3930 (MBM); ibídem, 24- 


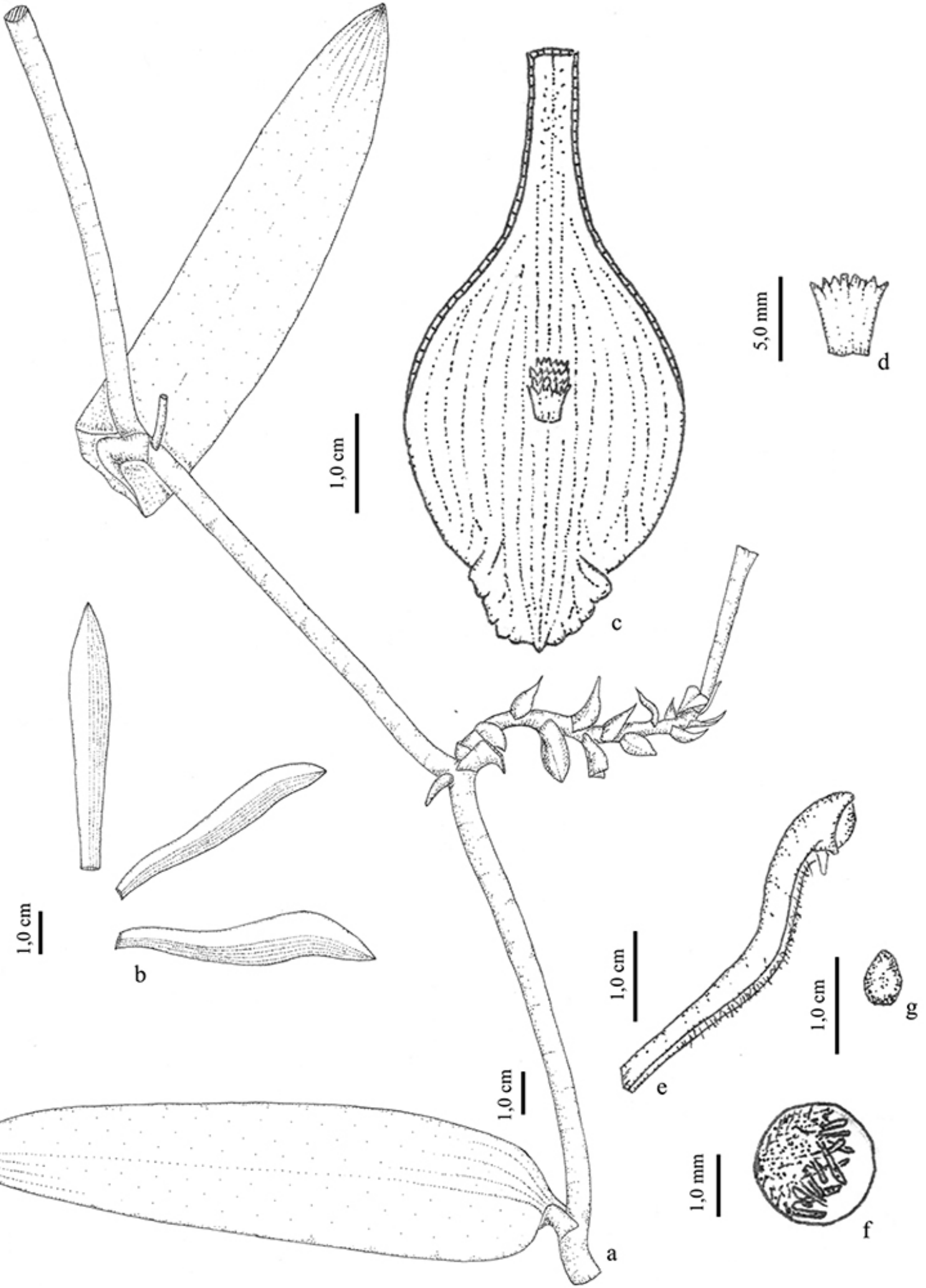

Figura 1. Vanilla bahiana Hoehne. a. hábito. b. perianto distendido. c. labelo distendido. d. detalhe do calo penicilado do labelo. e. coluna em vista lateral. f. detalhe dos tricomas do ventre da coluna. g. antera em vista frontal. (M.E. Engels 3755).

Figure 1. Vanilla bahiana Hoehne. a. habit. b. distended perianth. c. distended lip. d. detail of the penicillate callus of the lip. e. column in lateral view. f. detail of trichomes of the ventral portion of the column. g. anther in frontal view. (M.E. Engels 3755). 


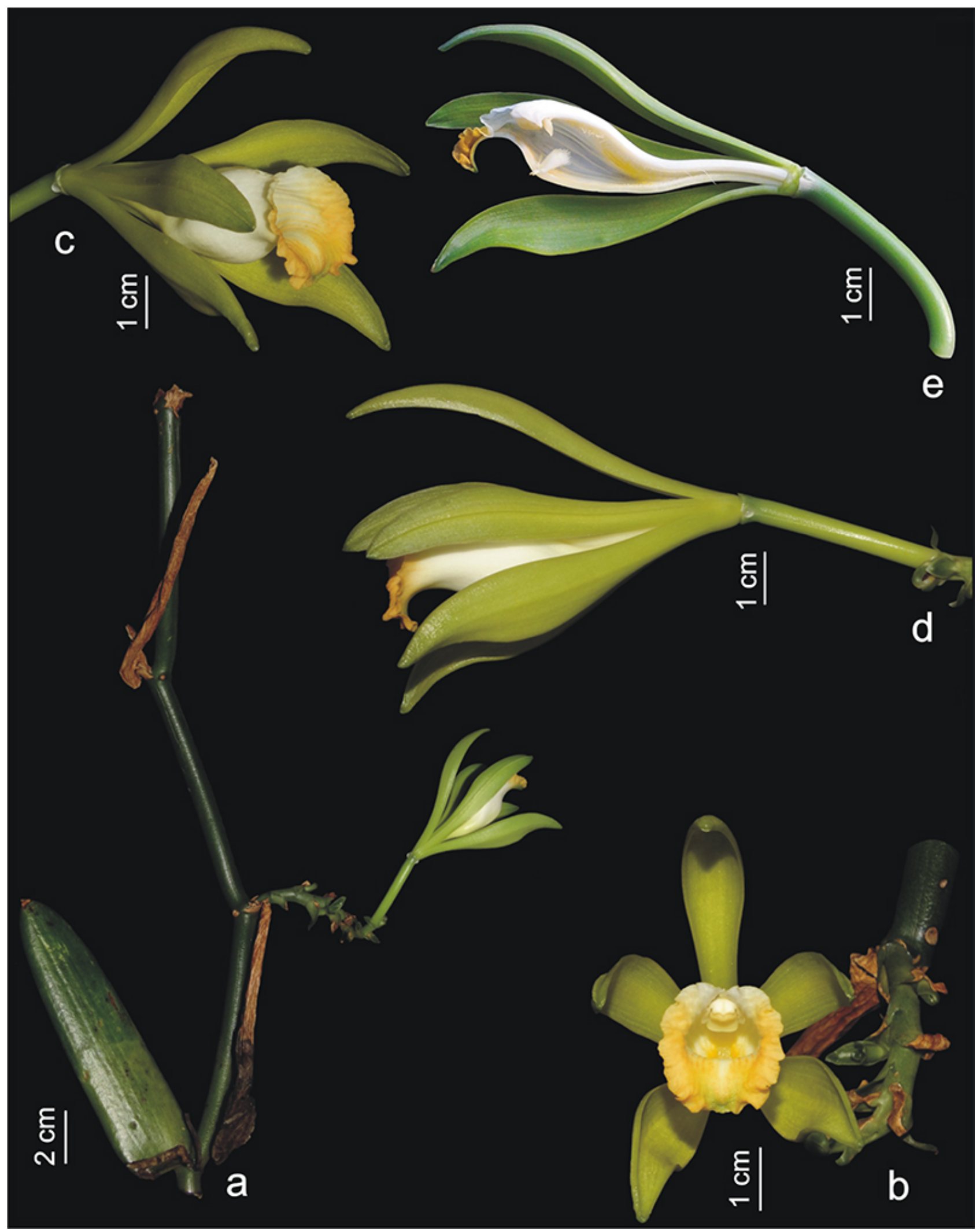

Figura 2. Vanilla bahiana Hoehne. a. hábito. b. inflorescência evidenciando flor em vista frontal. c-e. flor em vista diagonal, lateral e seccionada, respectivamente. Fotos: M.E. Engels.

Figure 2. Vanilla bahiana Hoehne. a. habit. b. inflorescence showing flower in frontal view. c-e. flower in diagonal, lateral ,and sectional views, respectively. Photos: M.E. Engels. 


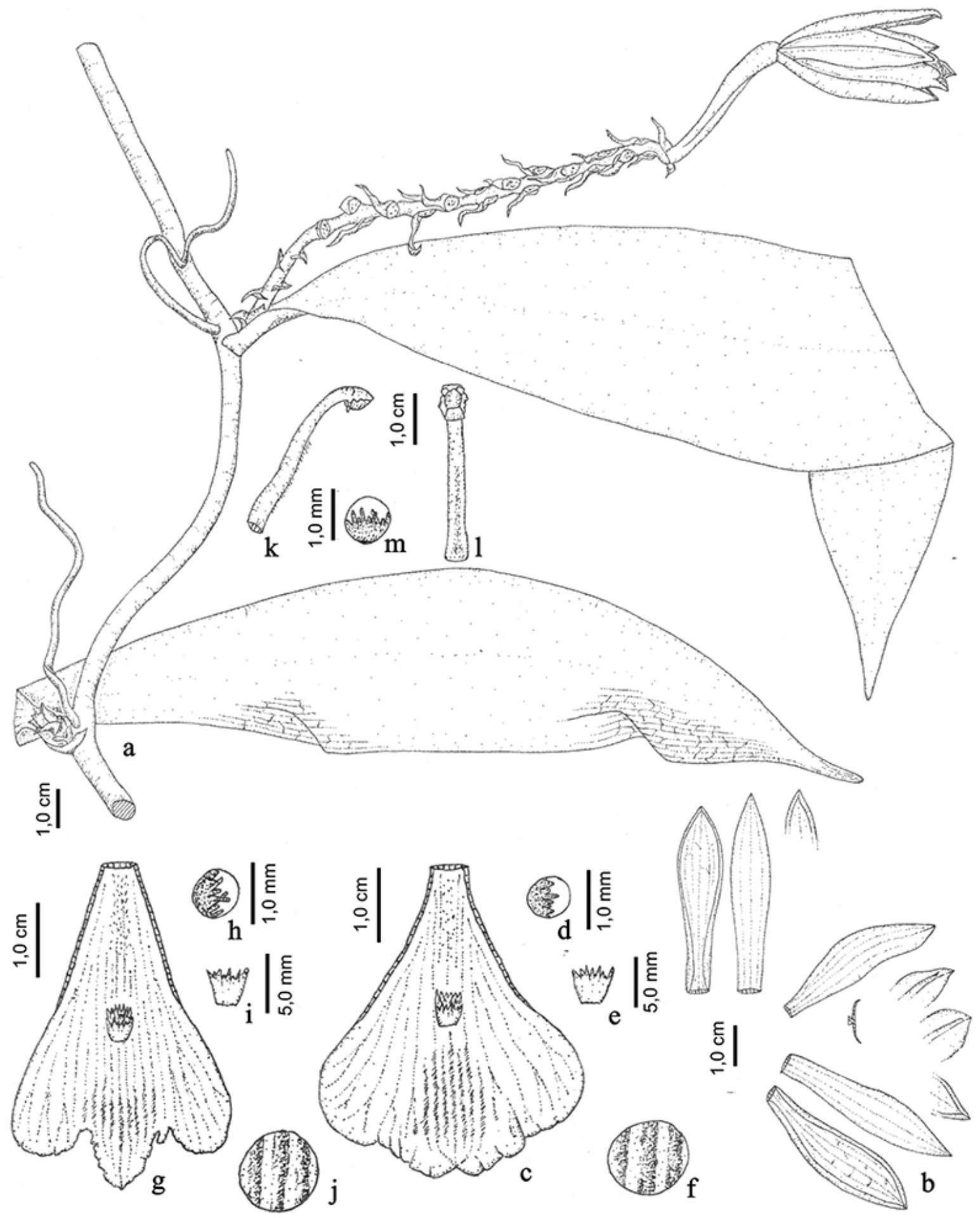

Figura 3. Vanilla cribbiana Soto Arenas. a. hábito. b. perianto distendido. c e g. labelo distendido. c. pertencente a uma das primeiras flores da raque. g. pertencente a última flor da raque. $\mathrm{d}$ e h. detalhe dos tricomas da base do labelo. e e i. detalhe dos calos penicilados do labelo. f e j. detalhe das carenas calosas do disco do labelo. k-1. coluna. k. vista lateral. 1. vista frontal. m. detalhe dos tricomas do ventre da coluna. (a, g-j. M.E. Engels 3930. b-f, k-m. M.E. Engels 6491).

Figure 3. Vanilla cribbiana Soto Arenas. a. habit. b. distended perianth. c and g. distended lip. c. belonging to one of the first flowers of the rachis. g. belonging to the last flower of the rachis. $d$ and $h$. detail of the trichomes of the lip base. e and i. detail of the penicillate callus of the lip. $f$ and $j$. detail of the callose carina of the lip disc. k-l. column. k. lateral view. l. frontal view. m. detail of trichomes of the ventral portion of the column. (a, g-j. M.E. Engels 3930. b-f, k-m. M.E. Engels 6491). 


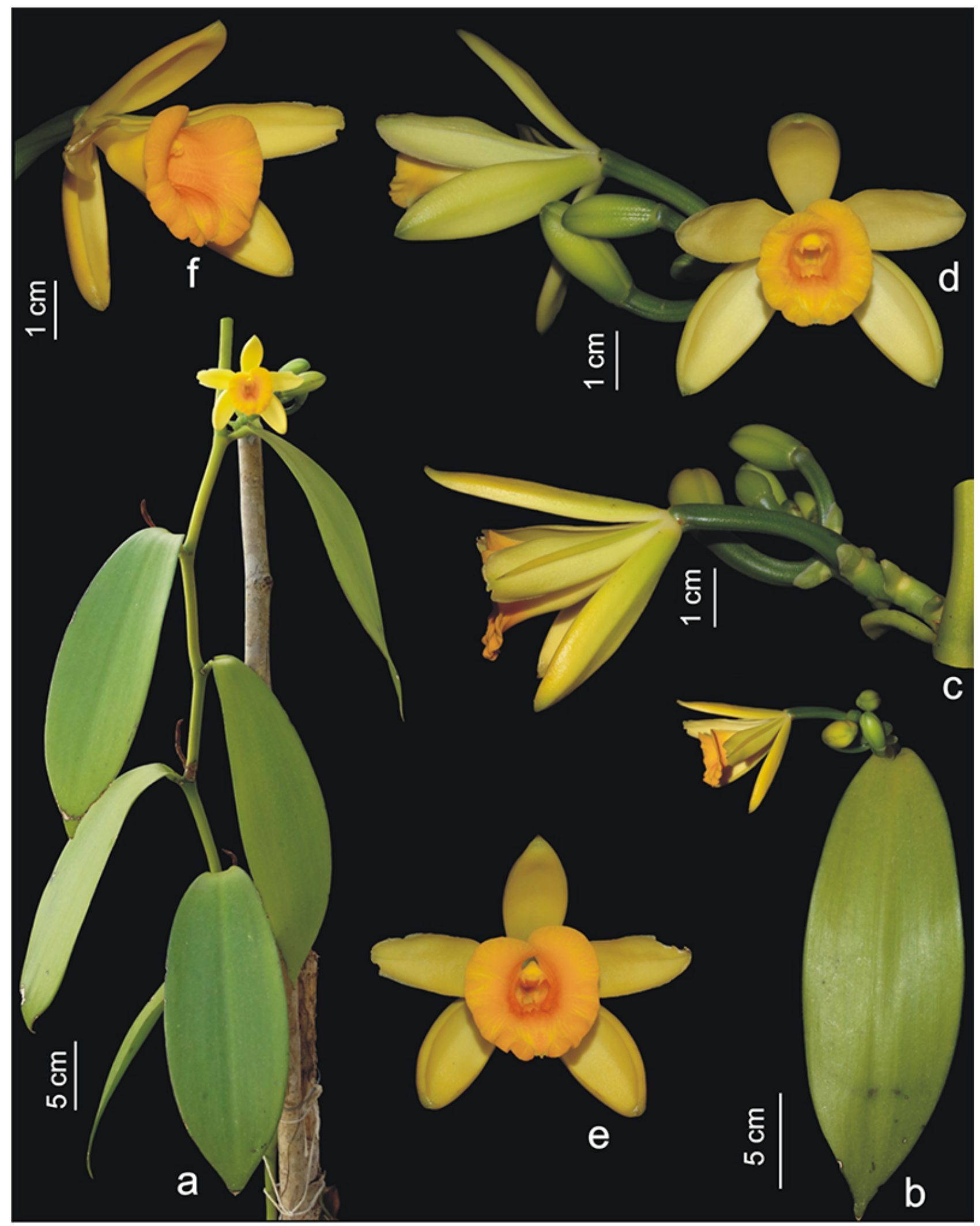

Figura 4. Vanilla cribbiana Soto Arenas. a. hábito. b. detalhe da folha em vista adaxial e inflorescência. c-d. inflorescências. e-f. flor em vista frontal e na diagonal, respectivamente. Fotos: M.E.Engels.

Figure 4. Vanilla cribbiana Soto Arenas. a. habit. b. detail of the adaxial view of leaf and inflorescence. c-d. inflorescence. e-f. flower in frontal and diagonal views, respectively. Photos: M.E. Engels. 
II-2016, fl., M.E. Engels 6491 (HERBAM, MBM). Nova Canaã do Norte, Resgate de FLORA da UHE Colíder, lote A de supressão. 16-I-2015, fr., M.E. Engels 2943 (MBM).

Vanilla cribbiana ocorre no México, Guatemala, Belize, Honduras (Soto Arenas \& Cribb 2010, Soto Arenas \& Dressler 2010, Govaerts 2016) e na região Norte do Brasil, no Estado do Pará (Koch et al. 2013, BFG 2015, 2018). No presente trabalho, é registrada pela primeira vez para a região Centro-Oeste, no Estado de Mato Grosso.

No Estado de Mato Grosso foi encontrada na Floresta Estacional Sempre Verde às margens do rio Teles Pires, na região Centro Norte do Estado, área de ecótono entre os domínios Amazônico e Cerrado. Suas ramagens densas e abundantes atingem a copa das árvores, a uma altura de ca. 8-12 m do solo. Floração em junho, frutificação em janeiro.

Soto Arenas e Dressler (2010) descreveram esta espécie para o México e América Central e logo em seguida foi registrada para o Brasil por Koch et al. (2013), sendo representada em herbários por poucos materiais. Além disso, Koch et al. (2013) observaram que a espécie foi tratada por Silva \& Silva (2010, pg. 490) como Vanilla gardneri Rolfe, deste modo, provavelmente ocorre em outros locais da Amazônia brasileira.

Pode ser reconhecida por suas folhas relativamente grandes em relação às espécies congêneres $(25,1-28,2 \mathrm{~cm}$ compr.); flores com pétalas e sépalas amarelas e labelo alaranjado; face abaxial das sépalas papilosas; labelo trilobado com base velutina e ápice truncado; calos penicilados no centro do labelo; carenas calosas espessadas no centro do terço apical; ventre da coluna pilosa; e ovário papiloso.

O material encontrado no Estado de Mato Grosso possui pequenas variações quando comparado com o já conhecido, como a coloração das flores (pétalas mais amarelas e labelo mais alaranjado) e pelo labelo mais aberto em posição natural. Além disso, observou-se que há variação na morfologia do labelo entre flores da base e do ápice da inflorescência, sendo menores e com labelo mais nitidamente lobado quando no ápice (Figura $3 \mathrm{c}$ e g).

Vanilla cristatocallosa Hoehne, Arq. Bot. Estado São Paulo, n.s., f.m., 1: 126. 1944. Tipo: BRASIL. Amazonas: Manaus. 25-X-1935, fl., A.Ducke s/n (Holótipo RB 37468).

= Vanilla aspericaulis Sambin \& Chiron, Richardiana, 15: 311. 2015. Tipo: GUYANA FRANCESA. Sudest du département, berg de l'Approuague, saut grand Machikou, 25-VII-2015, fl., V. Pelletier V 066 VP00902 (CAY), syn. nov.

Figuras 5-6

Erva hemiepífita, escandente. Raízes ca. 0,2 cm espessura, cilíndricas, castanhas. Caule 0,5-0,7 cm espessura, cilíndrico, inconspicuamente rugoso, escandente, verde; entrenós 6,5-12 cm compr. Folhas 8,5-15,2 2 2,2-3,5 cm, planas, estreitamente oblanceolado-elipsoides, levemente carnosas, base aguda, ápice agudo-cuspidado. Inflorescência 3,5-4 × 0,7-0,8 cm, racemosa, axilar, multiflora (9-flora). Flor com ovário+pedicelo 3,7-6,2 × 0,4-0,5 cm, cilíndrico, liso, alva com ápice verdeclaro; sépala dorsal 5,8-6,7 × 1,5-1,9 cm, elíptica, base aguda, margem inteira, ápice obtuso-cuculado, face abaxial lisa, amarelo esverdeada; sépalas laterais 5,2-5,8 × 1,8-2,2 cm, elíptica, base aguda, margem inteira, ápice obtuso-cuculado, face abaxial lisa, amarelo-esverdeadas; pétalas 5,6-6,3 × 1,6$1,7 \mathrm{~cm}$, elíptico-oblanceoladas, base aguda, margem inteira, ápice obtuso-arredondado, amarelo-esverdeadas; labelo 4,75,6 × 3,4-4 cm, parcialmente adnato à coluna, âmbito geral oblongo-oblanceolado, trilobado, alvo com ápice amarelo; lobos laterais 4,1-4,5 $\times 1,1-1,3 \mathrm{~cm}$, obovais, margem sinuada e recortada próximo ao sino; lobo central 1-2 × 1,4-1,6 cm, largoarredondado, ápice retuso, margem sinuada; carena central velutina na base, com calos peniciladosno centro, ca. $3 \mathrm{~mm}$ compr., e fimbrias do ápice até os calos penicilados, fimbrias 4-5 mm compr., furcados no ápice, se tornando simples para o centro. Coluna 3,2-3,4 $\times 0,4-0,5 \mathrm{~cm}$, subcilíndrica, densamente pilosa no ventre, da metade ao ápice, alva; tricomas 1-2 mm comp., alvos. Antera 0,3-0,4 ×0,3 cm, séssil, subquadradaelipsoide, alva. Fruto não visto.

Material examinado: BRASIL. Mato Grosso: Itaúba, Resgate de Flora da UHE Colíder, Lote I de supressão (Ilha), 05-XII-2015, fl., M.E. Engels 3913 (HERBAM, MBM, TANG).

Vanilla cristatocallosa ocorre no Brasil e na Guyana Francesa, sendo conhecida no Brasil até o momento apenas para a Região Norte, no Estado do Amazonas (BFG. 2015, 2018). Sendo um novo registro de distribuição geográfica para a região Centro-Oeste, no Estado de Mato Grosso. Esta espécie foi coletada pela primeira vez por Adolf Ducke em 1935 na região de Manaus-AM, sendo este material utilizado por Hoehne (1944) para descrever a espécie, desde então, não foram mais citadas novas coletas. No entanto, $V$. cristatocallosa provavelmente já foi recoletada mais vezes no Norte do país, pois Silva \& Silva (2010, pg. 492-493) trataram seu material como $V$. penicillata Garay \& Dunsterv., contudo, difere desta pelas folhas desenvolvidas ( $v s$. folhas rudimentares); labelo com lobos laterais arredondados (vs. obtusos) e lobo central com margem fimbriada e superfície pilosa ( vs. lobo central com margem sinuada e carenas centrais fimbriadas). Para mais informações sobre $V$. penicillata, consultar Dunsterville \& Garay (1965).

No Estado de Mato Grosso foi encontrada na Floresta Estacional Sempre Verde às margens do rio Teles Pires, na região Centro Norte do Estado de Mato Grosso, área de ecótono entre os domínios Amazônico e Cerrado. Nesta área, vegeta em ilhas e nas margens imediatas do rio, com ramagens chegando a copa das árvores, a uma altura entre 5-10 m do solo. Floração em dezembro.

Recentemente, Vanilla cristatocallosa foi sinonimizada sob V. cristagalli Hoehne por Soto Arenas \& Cribb (2010), contudo permanece como aceita na Flora do Brasil 2020 (2020, em construção) e BFG $(2015,2018)$. Após o estudo das obras de Hoehne $(1944,1945)$ e analisar 


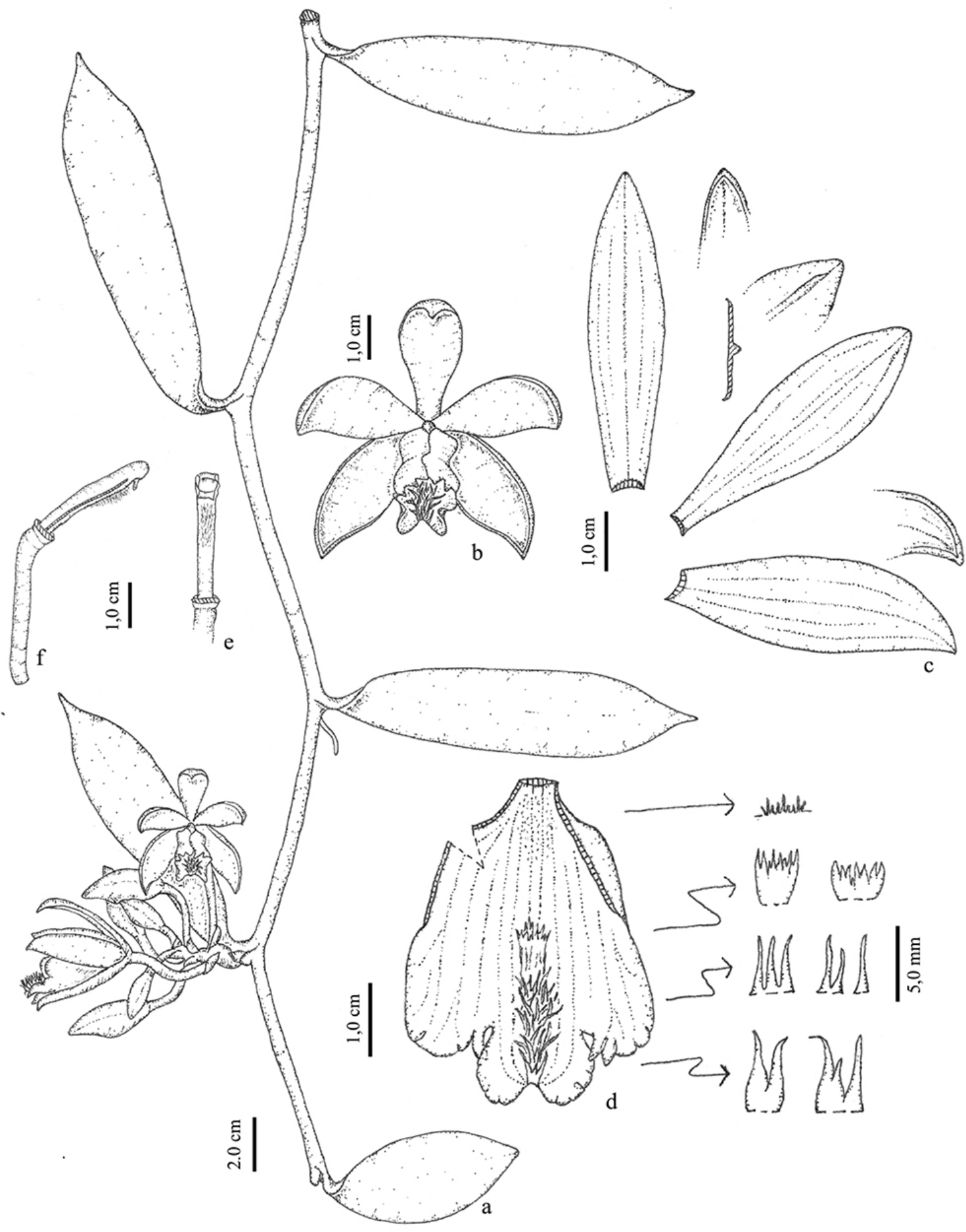

Figura 5. Vanilla cristatocallosa Hoehne. a. hábito. b. flor em vista frontal. c. perianto distendido. d. labelo distendido e respectivos calos penicilados e fimbrias. e. coluna em vista frontal. f. ovário + pedicelo e coluna em vista lateral. (M.E. Engels 3913).

Figure 5. Vanilla cristatocallosa Hoehne. a. habit. b. flower in frontal view. c. distended perianth. d. distended lip and respective penicillate callus and fimbriae. e. column in frontal view. f. ovary + pedicel and column in lateral view. (M.E. Engels 3913).

o material herborizado de V. cristagalli (A.Ducke $s / n$ RB 14512 [holótipo] e C.N.Fraga 3098 [RB]) e de $V$. cristatocallosa (A.Ducke s/ $n$ RB 37468 [holótipo]), bem como do material fresco, foi possível considerar as entidades como táxons distintos, restabelecendo $V$. cristatocallosa como espécie autônoma.

Vanilla cristatocallosa difere de $V$. cristagalli pelas folhas estreitamente oblanceolado-elipsoides (vs. elípticas); lobos 


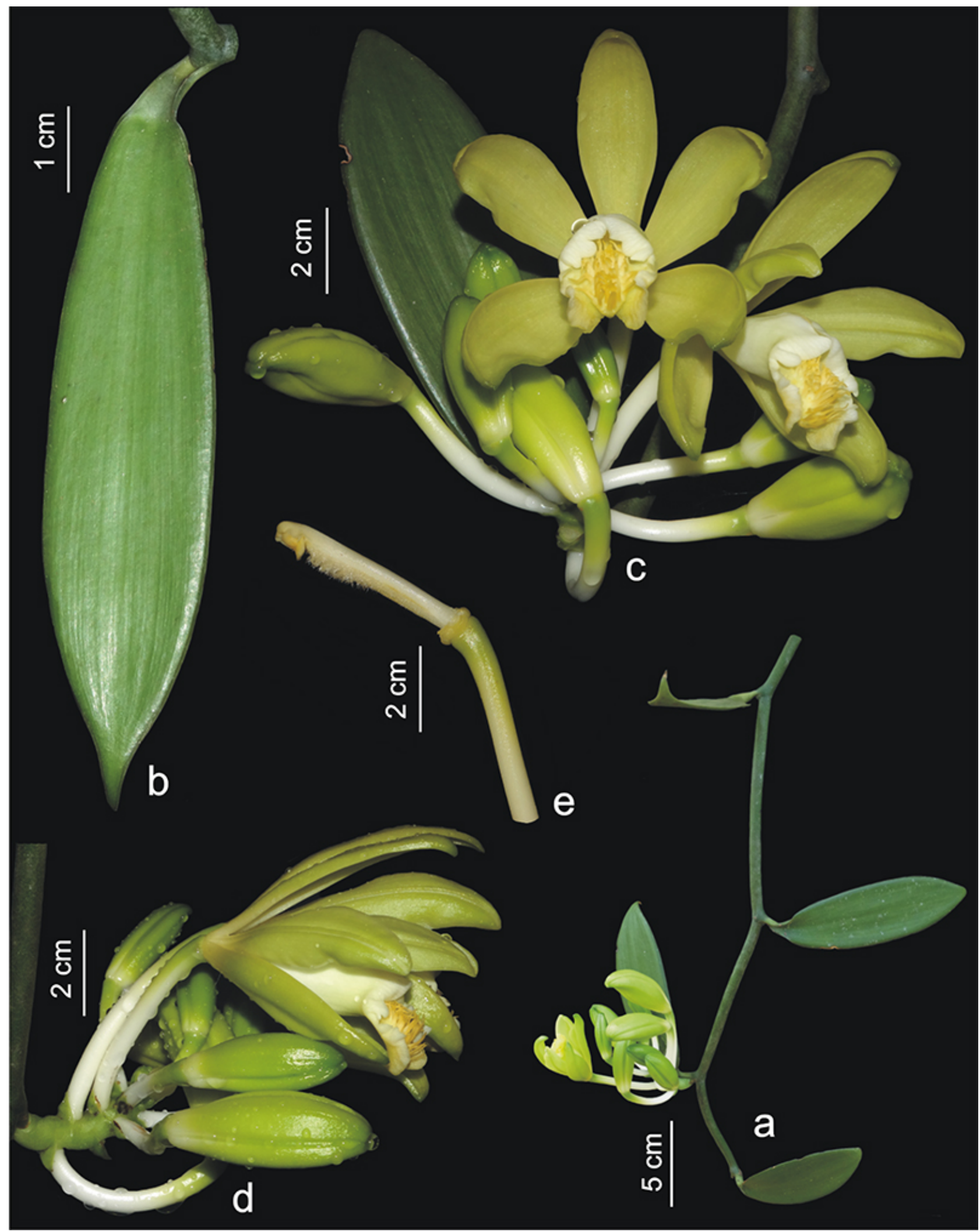

Figura 6. Vanilla cristatocallosa Hoehne. a. hábito. b. folha em vista adaxial. c-d. inflorescências. e. coluna e ovário + pedicelo em vista lateral. Fotos: M.E.Engels.

Figure 6. Vanilla cristatocallosa Hoehne. a. habit. b. leaf, adaxial view. c-d. inflorescence. e. column and ovary + pedicel in lateral view. Photos: M.E. Engels. 
laterais do labelo com margens próximas aos sinos recortadas (vs. lobos laterais com margens inteiras); carena central do labelo velutina na base, com calos penicilados no centro e fimbrias do ápice até os calos penicilados ( $v s$. carena central com calos penicilados no centro e fimbrias apenas no ápice).

Vanilla aspericaulis Sambin \& Chiron foi descrita em 2015 para a Guiana Francesa (Sambin \& Chiron 2015). Estes autores provavelmente compararam $V$. aspericaulis com a circuscrição original do nome $V$. cristagalli, não levando em consideração as características de $V$. cristatocallosa, que havia sido sinonimizada sob $V$. cristagalli por Soto Arenas $\&$ Cribb (2010), sendo as características descritivas de $V$. aspericaulis similares às de $V$. cristatocallosa.

$\mathrm{O}$ epíteto de $V$. aspericaulis se refere à aparência rugosa do caule, que se deve a presença de grânulos esbranquiçados nos entrenós (Sambin \& Chiron 2015). Essa característica, também pode ser observada em V. cristatocallosa, bem como o mesmo formato e coloração das estruturas florais, incluindo a pilosidade ventral da coluna, a posição e a forma das fimbrias e calos penicilados no labelo. Portanto, tomando como base as afinidades morfológicas entre estas, propomos a redução de $V$. aspericaulis como sinônimo de $V$. cristatocallosa.

\section{Agradecimentos}

À Companhia Paranaense de Energia Elétrica (COPEL), por autorizar a publicação dos dados aqui contidos. Ao consorcio CIA Ambiental e seus colaboradores. Á Claudio Nicoletti de Fraga, por toda ajuda e discussões durante a elaboração do presente estudo. À curadoria do Herbário CAY, por disponibilizar informações e material digitalizado de Vanilla aspericaulis Sambin \& Chiron.

\section{Literatura citada}

BFG (The Brazil Flora Group). 2015. Growing knowledge: an overview of Seed plants diversity in Brazil. Rodriguésia 66: 1085-1113.

BFG (The Brazil Flora Group). 2018. Brazilian Flora 2020: Innovation and collaboration to meet Target 1 of the Global Strategy for Plant Conservation (GSPC). Rodriguésia 69: 1513-1527.

Dunsterville, G.C.K. \& Garay, L.A. 1965. Venezuelan Orchids Illustrated III. Andre Deutsch, Londres.

Engels, M.E. \& Ferneda Rocha, L.C. 2016. Vanilla appendiculata (Orchidaceae): primeiro registro para o estado do Mato Grosso, Brasil. Rodriguésia 67: 855-858.

Fraga, C.N. 2002. Notas taxonômicas para espécies brasileiras de Vanilla Mill. (Orchidaceae). Boletim do Museu de Biologia Mello Leitão (Nova Série) 13: 45-52.
Ferreira, A.W.C., Oliveira, M.S., Silva, E.O., Campos, D.S., Pansarin, E.R. \& Guarçoni, E.A.E. Vanilla bahiana Hoehne and Vanilla pompona Shiede (Orchidaceae-Vanilloideae): two new records from Maranhão state, Brazil. Check List 13: 1131-1137.

Fidalgo, O. \& Bononi, V.L.R. 1989. Técnicas de coleta, preservação e herborização de material botânico. Reimpressão. Instituto de Botânica, São Paulo.

Flora do Brasil 2020 em construção. Jardim Botânico do Rio de Janeiro. Disponível em http://floradobrasil.jbrj. gov.br (acesso em 10-III-2020).

Gonçalves, E.G. \& Lorenzi, H. 2011. Morfologia vegetal: organografia e dicionário ilustrado de morfologia das plantas vasculares. 2 ed. Instituto Plantarum de Estudos da Flora, Nova Odessa.

Govaerts, R. 2017. World Checklist of Orchidaceae. Facilitated by the Royal Botanic Gardens, Kew. Disponível em www.kew.org/wcsp/monocots (acesso em 31-X-2019).

Hoehne, F.C. 1944. Orchidaceas novas para a flora do Brasil, dos herbários do Inst. de Botânica, Jardím Botânico, Rio de Janeiro, e comissão de lingas letegráficas, estratégicas de Mato-Grosso ao Amazonas. Arquivos de Botânica do Estado de São Paulo 1: 125-134.

Hoehne, F.C. 1945. Orchidaceas. In: Hoehne, F.C. Flora Brasílica 8, v. 12, parte II. Gráfica F. Lanzara, São Paulo.

Hoehne, F.C. 1950. Algumas novidades da flora do Brasil Áustro-Oriental entre Orchidaceas e Convolvulaceas. Arquivos de Botânica do Estado de São Paulo 2: 105-110.

Koch, A.K., Fraga, C.N., Santos, J.U.M., Ilkiu-Borges, A.L. 2013. Taxonomic notes on Vanilla (Orchidaceae) in the Brazilian Amazon, and the Description of a New Species. Systematic Botany 38: 975-981.

Petini-Benelli, A. \& Vaz-de-Melo, F.Z. 2013. Orquídeas da Chapada dos Guimarães, Mato Grosso, Brasil. Field guide of Field Museum, Chicago, EUA.

Sambin, A. \& Chiron, G.R. 2015. Deux nouvelles espéces de Vanilla (Orchidaceae) de Guyane française. Richardiana 15: 306-316.

Silva, M.F.F. \& Silva, J.B.F. 2010. Orquídeas nativas da Amazônia Brasileira II. Universidade Federal Rural da Amazônia / Museu Paraense Emílio Goeldi, Belém.

Soto Arenas, M.A. \& Cribb, F. 2010. A new infrageneric classification and synopsis of the genus Vanilla Plum. ex Mill. (Orchidaceae: Vanillinae). Lankesteriana 9: 355-398.

Soto Arenas, M.A. \& Dressler, R. 2010. A revision of the Mexican and Central American species of Vanilla Plumier ex Miller with a characterization of their its region of the nuclear ribosomal DNA. Lankesteriana 9: 285-354.

Thiers, B. 2019. Index Herbariorum. Part I: The herbaria of the world. New York Botanical Garden. Disponível em http://sweetgum.nybg.org/ih/ (acesso em 31-X-2019). 